\title{
Height and skeletal maturity in children with newly-diagnosed juvenile-onset diabetes
}

\author{
A D EDELSTEN, I A HUGHES, S OAKeS, I R S GORDON, AND D C L SAVAGE
}

Bristol Royal Hospital for Sick Children

SUMMARY Height and skeletal maturity scores (TW 2) were determined in 77 diabetic children at diagnosis and again in 48 of them after 1 to 4 years on insulin treatment. Boys, especially those of prepubertal age, were tall at onset. Girls had normal stature, but showed significant growth retardation after treatment. Skeletal maturity was appreciably advanced in both sexes at diagnosis, and on treatment returned to normal only in boys. Girls maintained their advanced skeletal maturity, resulting in an increased disparity between height and skeletal maturity. The results of this study suggest that a prediabetic metabolic abnormality may enhance skeletal maturity in children with diabetes and continues to operate in girls after treatment, despite a reduced growth rate.

Tall stature has often been reported in children presenting with juvenile-onset diabetes. ${ }^{1-6}$ Furthermore, a group of diabetic children was shown to be appreciably heavier at age 1 year than a control group. ${ }^{7}$ Women with maturity-onset (insulinindependent) diabetes tend to have large babies during their prediabetic years, ${ }^{8}$ as do women with juvenile-onset (insulin-dependent) diabetes, according to one report. ${ }^{9}$ These observations suggest that a disorder of carbohydrate metabolism may exist for some time before the clinical onset of diabetes. Advanced skeletal maturity has been reported in boys treated for less than 6 years, ${ }^{10}$ but there are few data of the disease at onset. This study reports on height and skeletal maturity in a group of diabetic children at presentation and gives preliminary results on the progression of these two factors with insulin treatment.

\section{Patients and methods}

39 boys and 38 girls were studied. All presented with juvenile-onset diabetes between September 1974 and January 1979. Their ages ranged between $1 \cdot 3$ and 15.3 years for boys, and between 2.5 and 12.9 years for girls (mean ages 8.73 and 9.01 years respectively). Skeletal maturity score was calculated in each child at diagnosis from an $x$-ray film of the left wrist by the TW 2 (RUS) method. ${ }^{11}$ A standard deviation (SD) score was calculated for each value using Tanner and Whitehouse SD standards for age and sex (unpublished data). Height SD scores were calculated using standard data, ${ }^{12}$ and the population charts of Tanner and Whitehouse for height and skeletal maturity score were used throughout the study. ${ }^{11-12}$ Statural growth and skeletal maturity scores were reassessed in 22 boys and 26 girls at intervals ranging from 1 to 4 years. Height and skeletal maturity SD scores wereanalysed by Student's $t$ test and when corrected for height age, the binomial probability test was used.

\section{Results}

Height. Height measurements at the onset of diabetes in these children are summarised in Table 1 and in Figs 1 and 2. Boys were tall, and 18 out of 22 less than 10 years of age were above the 50th centile. Girls showed no increase in stature at presentation, and none had a height SD score above 1 (Fig. 2).

Table 1 Height at onset and after treatment in children with juvenile-onset diabetes

\begin{tabular}{|c|c|c|c|c|}
\hline & \multirow[t]{2}{*}{ Sex } & \multicolumn{2}{|l|}{ Number } & \multirow[t]{2}{*}{ Mean SD score* } \\
\hline & & $\begin{array}{l}>50 t h \\
\text { centile }\end{array}$ & $\begin{array}{l}<50 \text { th } \\
\text { centile }\end{array}$ & \\
\hline At onset & $\begin{array}{l}\mathbf{M} \\
\mathbf{F}\end{array}$ & $\begin{array}{l}25 \\
19\end{array}$ & $\begin{array}{l}14 \\
19\end{array}$ & $\begin{array}{l}+0.46(\mathrm{P}<0.01) \\
-0.14(\mathrm{NS})\end{array}$ \\
\hline After treatment & $\begin{array}{l}\mathbf{M} \\
\mathbf{F}\end{array}$ & $\begin{array}{r}12 \\
5\end{array}$ & $\begin{array}{l}10 \\
21\end{array}$ & $\begin{array}{l}+0.07(\mathrm{NS}) \\
-0.47(\mathrm{P}<0.01)\end{array}$ \\
\hline
\end{tabular}

NS = not significant.

SD score is calculated from the formula SD score $=(X-\bar{x}) / S$, where $X$ is the measurement in the individual, and $\bar{x}$ and $S$ are the mean and SD for a control population of the same age and sex. 


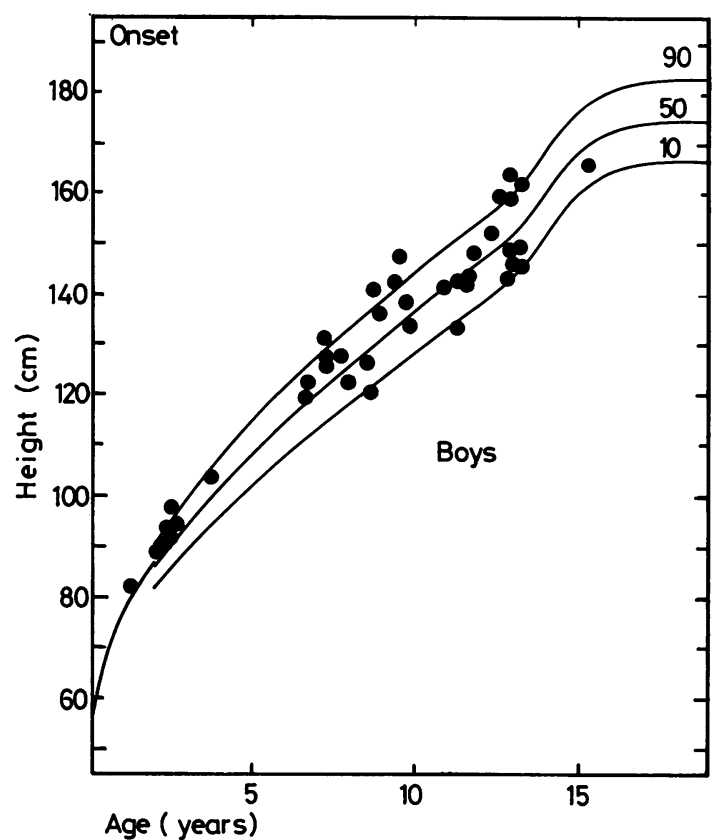

Fig. 1 Height and age at diagnosis for 39 boys with juvenile-onset diabetes.

After treatment, boys were no longer taller than the standard population. Height SD score had fallen in 17 of the 22 boys reassessed, whose ages ranged from 2.9 to 16.5 (mean 10.63 ) years. A similar, but greater fall in height SD score occurred in the 26 girls reassessed (Fig. 2). Their ages ranged from $7 \cdot 05$ to $15 \cdot 8$ (mean 11.60 ) years. They were now short (Table 1) with only 5 girls above the 50th centile (Fig. 2).

Skeletal maturity. Skeletal maturity scores at onset are shown in Table 2 and in Figs 3, 4, and 5. The scores were significantly advanced at diagnosis in boys and girls. When compared with the height age (age at which the height is at the 50th centile on a standard chart) the scores in boys were still advanced. A significant number were above the 75th and 90th centiles when the data were analysed using the binomial probability test $(P<0 \cdot 01)$. Skeletal maturation was not advanced in boys under 6 years of age, even though they were tall (Fig. 3). This may result from less accurate determination of skeletal maturation in young children.

In girls under 10 years of age at diagnosis, 18 out of 20 were above the 50th centile for skeletal maturity (Fig. 4). Advanced skeletal maturation

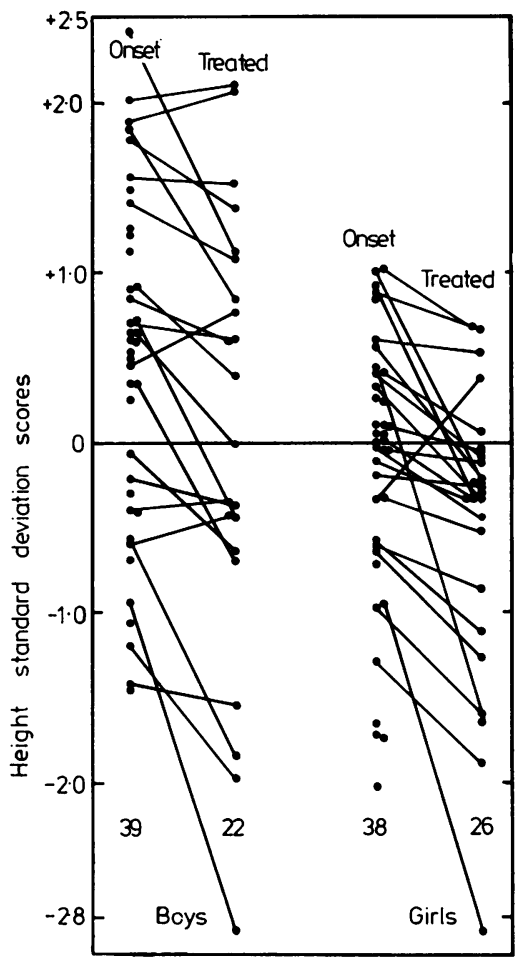

Fig. 2 Height SD scores at onset and after treatment in boys and girls.

Table 2 Skeletal maturity scores at onset and after treatment in children with juvenile-onset diabetes

\begin{tabular}{lllll}
\hline & Sex & \multicolumn{2}{l}{ Number } & \multicolumn{2}{c}{ Mean SD score } \\
\cline { 3 - 5 } & & $\begin{array}{c}>50 \text { sh } \\
\text { centile }\end{array}$ & $\begin{array}{c}<50 \text { ch } \\
\text { centile }\end{array}$ \\
\hline At onset & M & 31 & 8 & $+0.76(\mathrm{P}<0.001)$ \\
& F & 28 & 10 & $+0.61(\mathrm{P}<0.01)$ \\
After treatment & M & 16 & 6 & $+0.47(\mathrm{NS})$ \\
& F & 19 & 7 & $+0.41(\mathrm{P}<0.025)$ \\
\hline
\end{tabular}

was more significant when the skeletal maturity score was compared with height age $(P<0.001)$ and reflects the tendency to reduced height for age at diagnosis in girls.

When reassessed after treatment, all except 3 of the 22 boys showed a reduction in skeletal maturity SD score (Fig. 5 and Table 2). By contrast the girls maintained a significant skeletal advance and increased further the disparity between height and skeletal maturity (Fig. 6). 


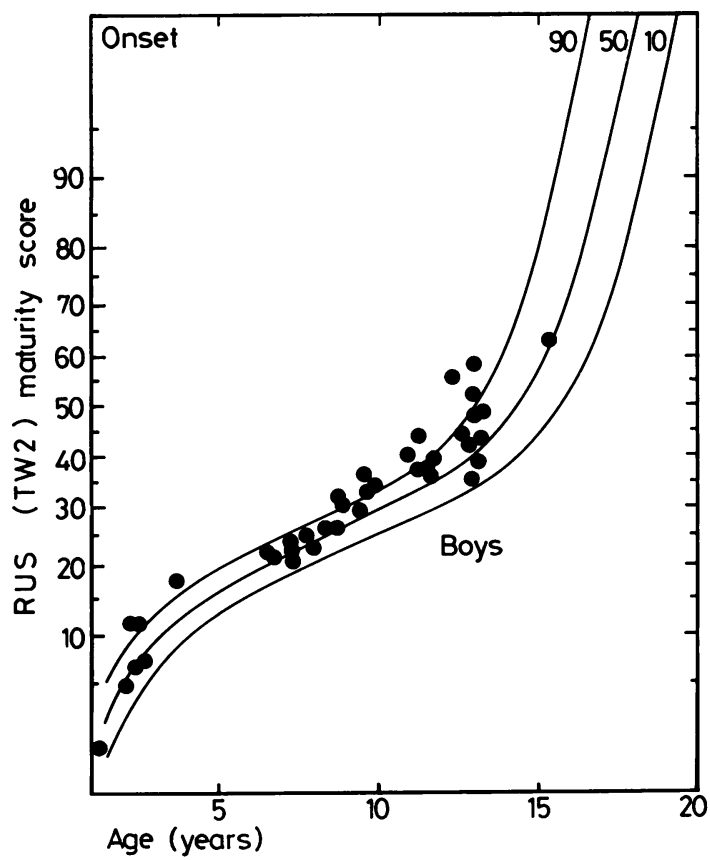

Fig. 3 Skeletal maturity scores at onset in 39 boys with juvenile-onset diabetes.

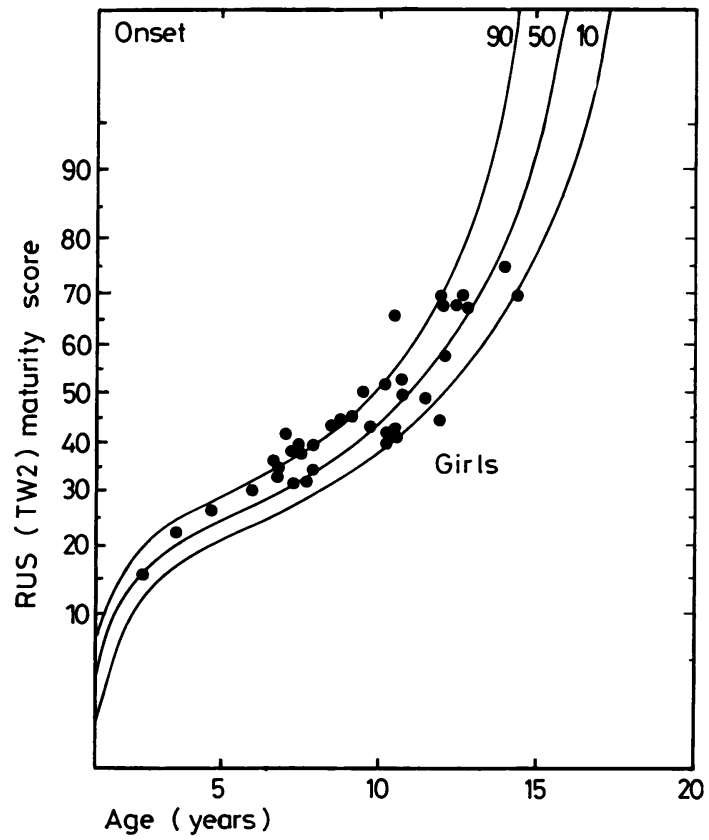

Fig. 4 Skeletal maturity scores at onset in 38 girls.

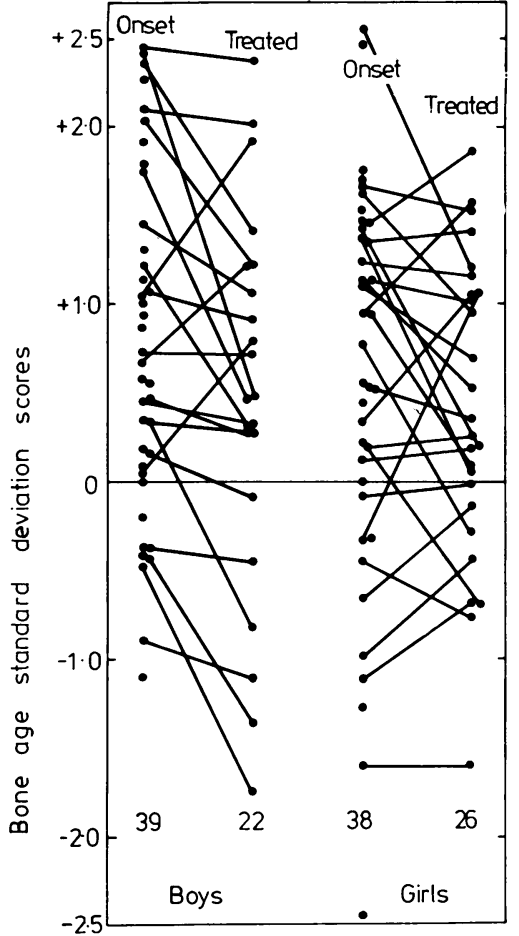

Fig. 5 Skeletal maturity SD scores at onset and after treatment.

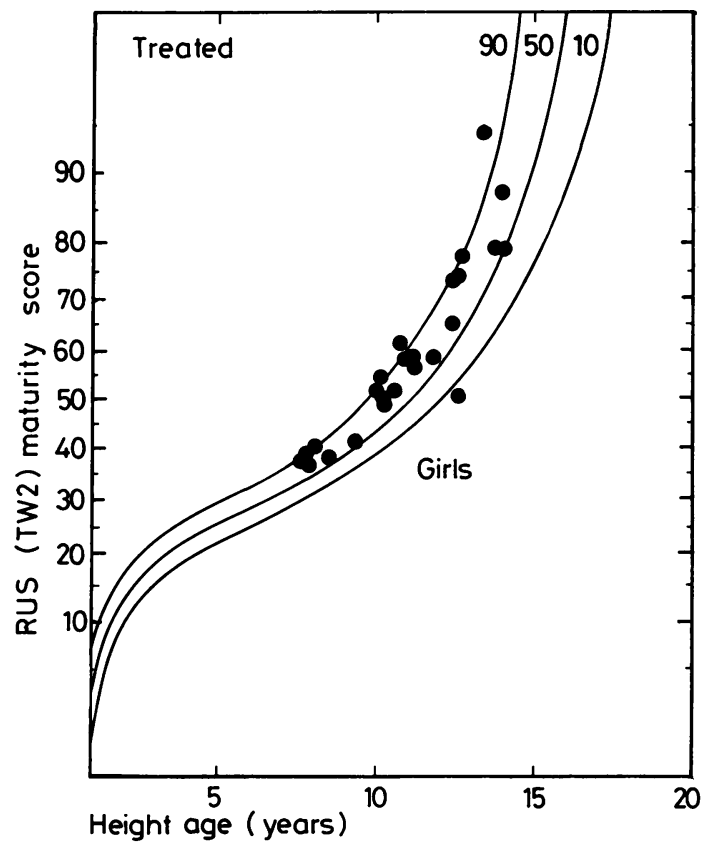

Fig. 6 Skeletal maturity scores in relation to height age after treatment in 26 girls with juvenile-onset diabetes. 


\section{Discussion}

The results of this study confirm previous reports of increased stature at onset of diabetes, particularly in boys under 10 years of age. ${ }^{613}$ Not all workers found that their children were tall at diagnosis. ${ }^{1014}$ For this study, there were no control data for height and skeletal maturity in healthy Bristol children. However, there is no reason to suspect that these children would show major differences from the population studied by Tanner and his colleagues.

In treated diabetic children, a reduced growth rate, especially at puberty, has been variously attributed to poor nutrition, inadequate control, ${ }^{15-16}$ delayed puberty, ${ }^{14}$ or to the duration of the disease. ${ }^{10}$ The boys in our study have shown a reduced rate of growth and skeletal maturity after treatment, such that height and skeletal maturation are now within normal limits. However, the poor growth in the girls on treatment, despite normal skeletal maturity rate, together with the experience of other workers, ${ }^{310}$ suggests that boys are also destined to show a continuing fall-off in height to subnormal values.

Vicens-Calvet et al. ${ }^{13}$ found normal bone age at the onset in a small mixed group of diabetic children using Tanner and Whitehouse standards and the TW 2 (RUS) method. This present study of a larger group of diabetic children, is the first detailed analysis of skeletal maturation at onset of the disease. The significant advancement in skeletal maturity was slightly greater in boys due in part to their tall stature. However, in both boys and girls skeletal maturity was disproportionately advanced in relation to height at onset. This is in keeping with the results of a cross-sectional study of skeletal maturation in diabetic boys during the first years of treatment. ${ }^{10}$ The concept of a prediabetic state of disordered metabolism gains further support from these observations. In addition, latent diabetic siblings of juvenile-onset diabetics can have delayed insulin responses to glucose, and abnormal carbohydrate tolerance for some years before symptoms appear. ${ }^{17}$

What likely endocrine factors could be operating to enhance skeletal maturation during the prediabetic state? Thyroid and sex steroid hormones have a strong influence on skeletal maturation. There are no data, either from this study or from others, to suggest that there may be abnormal circulating concentrations of these hormones in the prediabetic state. Hyperinsulinaemia and growth hormone excess are other possibilities. Hypoglycaemic episodes can precede overt diabetes ${ }^{18}$ insulin is known to be a potent growth and anabolic hormone.
Increased peak and mean levels of growth hormone have also been observed in untreated juvenile-onset diabetes. ${ }^{19}$ The increased plasma concentrations of these hormones are reduced to normal after insulin treatment. The reduction in height and skeletal maturity score, particularly in the boys, after treatment, may be associated with plasma levels of anabolic hormones returning to normal after being raised during the prediabetic state.

Measurement of height and skeletal maturity score may prove to be a useful phenotypic marker for genetically predisposed diabetic children, such as siblings of known diabetics. Further application of skeletal maturity scores and adult height predictions at various periods during the course of treatment with insulin may result in an improved method for assessing control in children with diabetes.

We record with regret the death of Dr Ian Gordon on 12 June 1979.

We thank Mr A O Hughes for statistical advice.

\section{References}

1 Ladd W S. Growth in children with diabetes mellitus. Am J Dis Child 1926; 32: 812-38.

2 Boyd J D, Nelson M V. Growth studies of children with diabetes mellitus. Am J Dis Child 1928; 35: 753-61.

3 Rabinowitch I M, Bazin E V. A statistical study of the rate of skeletal growth in juvenile diabetes. Arch Dis Child 1929; 4: 125-8.

4 Craig J O. Growth as a measurement of control in the management of diabetic children. Postgrad Med J 1970; 46: 607-10.

5 Pond H. Some aspects of growth in diabetic children. Postgrad Med J 1970; 46: 616-23.

6 Drayer N M. Height of diabetic children at onset of symptoms. Arch Dis Child 1974; 49: 616-20.

7 Baum J D, Ounsted M, Smith M A. Letter: Weight gain in infancy and subsequent development of diabetes mellitus in childhood. Lancet 1975; ii: 866.

8 Irvine W J. Classification of idiopathic diabetes. Lancet 1977; i: 638-42.

- Steel J M, Gray R S, Clarke B F. Obstetric history of diabetes: its relevance to the aetiology of diabetes. $\mathrm{Br}$ Med J 1979; i: 1303-5.

10 Evans N, Robinson V P, Lister J. Growth and bone age of juvenile diabetics. Arch Dis Child 1972; 47: 589-93.

11 Tanner J M, Whitehouse R H, Marshall W A, Healey M J R, Goldstein H. Assessment of skeletal maturity and prediction of adult height (TW2 method). London: Academic Press, 1975: 78-93.

12 Tanner J M, Whitehouse R H, Takaishi M. Standards from birth to maturity for height, weight, height velocity, and weight velocity: British children 1965. Parts I and II. Arch Dis Child 1966; 41: 454-71, 613-35.

13 Vicens-Calvet E, Sureda J, Blanco M G, Pineda C. Growth and maturity in diabetic children before puberty. In: Chiumello $\mathrm{G}$, Laron $\mathrm{Z}$, eds. Recent progress in pediatric endocrinology. London: Academic Press, 1977: 313-9. 
44 Edelsten, Hughes, Oakes, Gordon, and Savage

14 Jivani S K M, Rayner P H W. Does control influence the growth of diabetic children? Arch Dis Child 1973; 48: 109-15.

15 Birkbeck J A. Growth in juvenile diabetes mellitus. Diabetologia 1972; 8: 221-4.

16 Williams M L, Savage D C L. Glycosylated haemoglobin levels in children with diabetes mellitus. Arch Dis Child 1979; 54: 295-8.

17 Fajani S S, Floyd J C, Jr, Tattersall R B, Williamson J R, Pek S, Taylor C I. The various faces of diabetes in the young. Arch Intern Med 1976; 136: 194-202.

18 Allen O P. Symptoms suggesting prodromal stage of diabetes mellitus. Ohio State Med J 1953; 49: 213-5.
19 Hansen A P, Johansen K. Diurnal patterns of blood glucose, serum free fatty acids, insulin, glucagon, and growth hormone in normals and juvenile diabetics. Diabetologia 1970; 6: 27-33.

Correspondence to $\mathrm{Dr}$ A D Edelsten, Northgate Hospital, Northgate Street, Great Yarmouth, Norfolk NR30 1BU.

Received 16 October 1979 